\title{
SEISMIC ANALYSIS AND DESIGN ASSISTED BY NUMERICAL SIMULATION OF SLENDER STEEL PORTAL FRAME STRUCTURES
}

\author{
${ }^{1}$ ALIA O. M. AHMED \& ${ }^{2}$ NIGEL D. P. BARLTROP \\ ${ }^{1}$ Sudan University of Science \& Technology, Sudan. \\ ${ }^{2}$ University of Strathclyde, UK.
}

\begin{abstract}
Lightweight (thin-walled or cold-formed) steel portal frame structure could be a popular and effective alternative to the traditional hot rolled structure and, with care to avoid buckling, could be used in earthquake areas owing to its economy and ease of fabrication and transportation, but no recommendations for seismic design of these structures is provided in the design codes. Accordingly, there is need for a lightweight design that is suitable for earthquake areas, which could be transported using lighter vehicles and erected quickly using smaller plant than is required for conventional hot rolled sections following an earthquake. The present paper shows some stages in the development of an earthquakeresistant frame, designed for by combining numerical finite element investigations with analytical check calculations based on EN 1993-1-3 for cold-formed steel members and EN 1993-1-1 for design of steel structures to estimate the loads on the frame structure within the use of EN 1998-1seismic design requirements. Although the initial buckling modes have been avoided, the frame still needs further modification to improve its ductility. It is planned to use this work to assist with the development of performance-based design recommendations for future structures that cover both thin-walled steel and cold-formed steel portal frame structures.
\end{abstract}

Keywords: cold-formed steel, portal frame, seismic design, steel, thin-walled structures

\section{INTRODUCTION}

Portal frame structures are widely used and have become the most often used structures for single storey non-residential buildings. However, there is a need for a lightweight design that is suitable for potential earthquake areas that could be easily transported and erected quickly following an earthquake and used for shelter, schools, hospitals, refugee camps etc. Likewise, they ought to be capable of resisting large aftershocks and could become a permanent building but might be removed and reused. Very light weight thin gauge steel construction is light but is likely to buckle under large deflections. Such a characteristic is not desirable during earthquakes.

In addition to that despite the establishment and development of codes for seismic design, they still lack design guidance for some types of structures. Lightweight steel portal frame structure systems could be an effective alternative to heavy steel, but no recommendations for seismic design of these structures is provided in the design codes. The design rules in the European code for cold-formed steel design [1] do not contain specific recommendations for seismic design of these structures. EN 1998-1 [2] does not specifically mention the use of thin-walled steel sections for seismic-resistant structures. However, it classifies thin gauge structures as low dissipative structures (e.g. low ductility) with a behaviour factor $q$ of values from 1.5 to 2.0. Assuming that such type of structures are made by 'elastic' sections (e.g. class 3 or class 4 ), a behaviour factor $q$ greater than 1.0 can be justified by overstrength and structural redundancy.

The present paper attempts to assist with the lack of seismic design guides of these structures by providing some recommendations for design rules for such type of structures. 


\section{REVIEW ON SEISMIC PERFORMANCE OF THIN-WALLED PORTAL}

Previous researchers have stated that light gauge steel structures, made with class 3 or class 4 sections, fabricated by cold forming or thin plate welding can be effectively used in seismicresistant structures mainly due to their reduced weight/strength ratios [3] and [4].

Traditional capacity design based on equivalent elastic static analysis with reduction factors $\mathrm{q}$ of values $1<\mathrm{q}<2$ can be used provided the overstrength of joints and structural redundancy are available [3].

Seismic response of light-gauge steel framing can be significantly improved if shear walls are used to resist horizontal forces [3]. Both experimental and numerical results by researchers in the literature sustain to classify light-gauge steel structures as low-dissipative (e.g. class L, q=1.5-2.0), as specified in EN 1998-1 [2]. Previous research showed the possibility of using light gauge steel as earthquake-resistant structure but with recommendation to use shear walls as a lateral resisting system due to the problems of stability and imperfection of light gauge steel.

\section{NUMERICAL INVESTIGATION}

This section presents computational simulation techniques using the commercially available finite element software ANSYS [5]. The main objective of this study is to investigate the response of a frame model to horizontal displacements, which will be used for the seismic design of the frame combined with code calculations check.

\subsection{Proposed models for the study}

The two-pitched roof single-storey frame building models considered in this study have the same overall structural configuration of nine identical, equally spaced, moment resistant frames. The building is $40 \mathrm{~m}$ long by $20 \mathrm{~m}$ wide for all the models. The steel frames are fixed at their columns bases and have a span of $20 \mathrm{~m}$ and are spaced at $5 \mathrm{~m}$, which leads to 8 bays or 9 frames (Fig. 1). The purlins are spaced equally at about $1.5 \mathrm{~m}$ and span between the steel frames. The columns are $6 \mathrm{~m}$ high and the distance from ground level to the apex of the frame is approximately $10 \mathrm{~m}$ for the first model (Fig. 2), while it is $6.875 \mathrm{~m}$ for the last model (Fig. 4).

The key features of this structural system were the use of creative built up cold-formed steel sections made from largest back-to-back lipped channel that can currently be rolled for the column and rafter members.

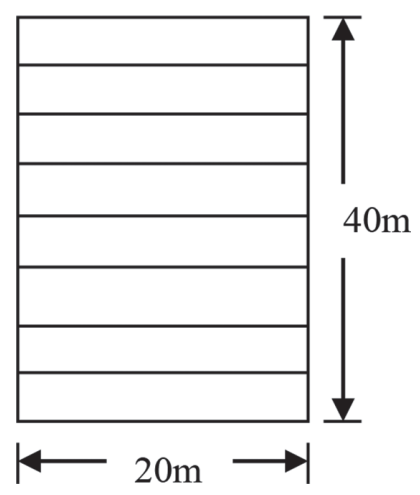

Figure 1: Plan of the building.

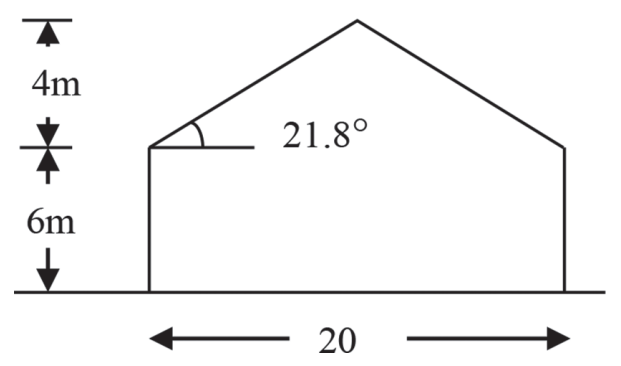

Figure 2: Portal frame for first model. 


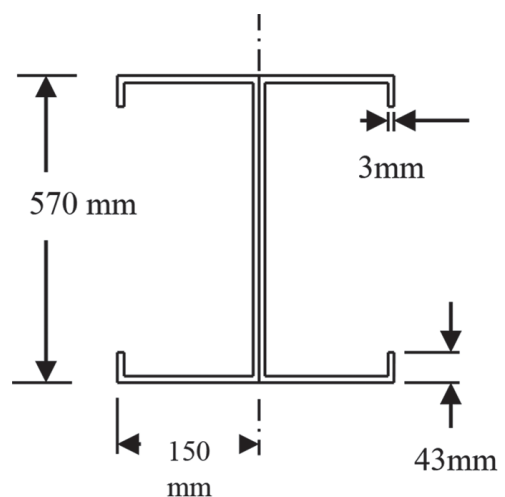

Figure 3: Dimensions of back- to back lip channel section used for column and rafter member for first model.

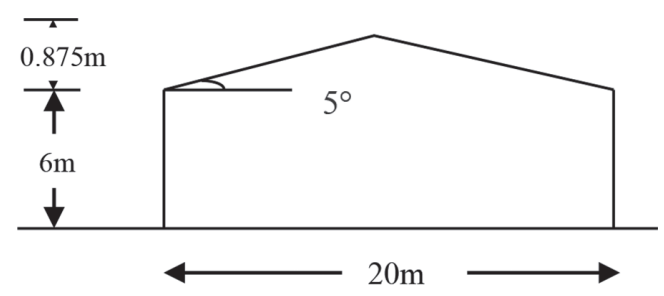

Figure 4: Portal frame for last model

The rafters in each frame for the first model have $570 \mathrm{~mm}$ total depth, the upper and lower flange width is $300 \mathrm{~mm}$, the thickness is $3 \mathrm{~mm}$ and there is a lip of $43 \mathrm{~mm}$. The columns of the frame have the same dimension of the rafters for the first model (see Fig. 3).

The rafters in each frame for the last modified model have $750 \mathrm{~mm}$ total depth, the upper and lower flange width is $500 \mathrm{~mm}$ with thickness $3 \mathrm{~mm}$ and lip of $53 \mathrm{~mm}$ (see Fig. 5).

The columns of the frames have $850 \mathrm{~mm}$ total depth and $6 \mathrm{~mm}$ web thickness, the upper and lower flange width is $650 \mathrm{~mm}$ with $3 \mathrm{~mm}$ thickness and $63 \mathrm{~mm}$ lip.

The first model used for the numerical investigation and used for the calibration of the seismic design is a frame of span $20 \mathrm{~m}$ with rigid joints and fixed at column bases, pitch $21.8^{\circ}$ as was explained in previous section (see Fig. 2).

The brackets for the joints for ridge and knees are $5 \mathrm{~mm}$ thickness from cold-formed steel (see Figs $6 \& 7$ ). The proposed connections are bolted connections. The connected members are connected together through cold-formed steel plate using welded bracket elements

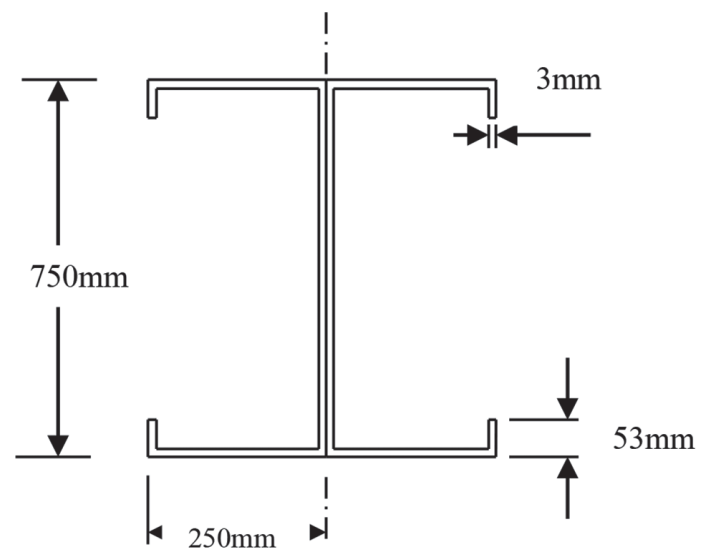

Figure 5: Dimensions of back to back lip channel section for rafter member for last model 


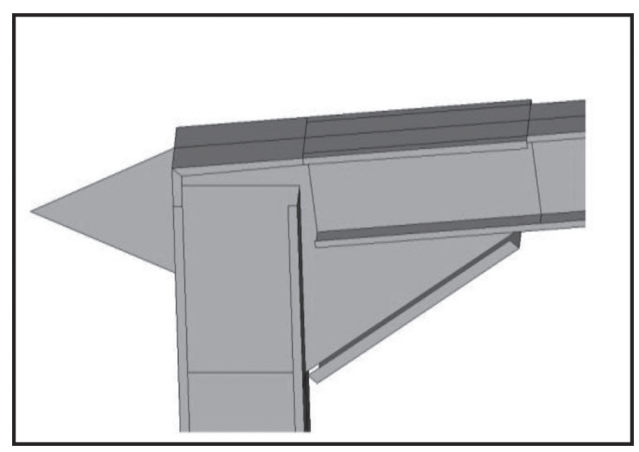

Figure 6: ANSYS model for knee connection

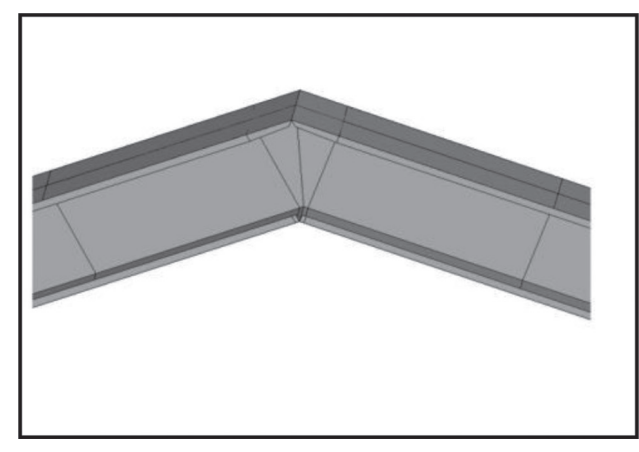

Figure 7: ANSYS model for ridge connection

$(\mathrm{S} 355: \mathrm{Fy}=355 \mathrm{~N} / \mathrm{mm} 2)$ and M20 grade 8.8 bolts. To achieve a good performance of the connections, the plate was enhanced with folding stiffeners.

A gap in the lower part of the plate was applied to avoid the interaction between the folding stiffeners and the frame members for the finite element model. For simplicity, the connections for knees and ridge were modelled in the finite elements model as rigid.

Extra, artificial external triangular brackets were added at the eaves as shown in Fig. 8 to prevent concentration of the stresses when applying loads at the corner nodes.

\subsection{Finite elements modelling of the frame}

The commercially available finite element software ANSYS [5] was used for the analyses of the frame structure models in this research project. Rafters, columns and brackets are modelled using the four-noded thin shell element SHELL181. SHELL181 is well-suited for linear, large rotation, and/or large strain nonlinear applications. The finite element mesh used for the frame is shown in Fig. 8. The mesh size used in the finite element model for the shell elements was around $25 \times 25 \mathrm{~mm}$.

The inelastic behaviour of the steel elements was considered using the von Mises yield criterion with isotropic yielding. Geometric nonlinearities: large displacement and P- $\delta$ effects were considered in the analyses. The stress-strain relationship is assumed to be elasticperfectly plastic with a Young's modulus of 205E3 MPa up to the yield strength followed by strain hardening with value of $1 \%$ of the Young's modulus, i.e. the tangent modulus is 2.05E3 MPa and a yield strength of $400 \mathrm{MPa}$.

The analysis involves subjecting the frame to monotonically increasing static lateral displacements as it is an efficient tool to describe the behaviour of the frame beyond the plastic zone or within the strain hardening region. The lateral displacements were used first to test the response of the frame to lateral displacement until failure as the earthquake effect on the structure is assumed to be horizontal without considering the gravity load.

\subsection{Some checking of the finite elements used}

To validate the finite element models, the analysis was carried for a steel thin plate of $350 \mathrm{~mm}$ length, $350 \mathrm{~mm}$ wide, $6 \mathrm{~mm}$ thick with Young's modulus, $\mathrm{E}=205 \mathrm{MPa}$ and poison ratio 0.3. The plate was assumed to be made of cold-formed steel and modelled with type 181 shell elements. 


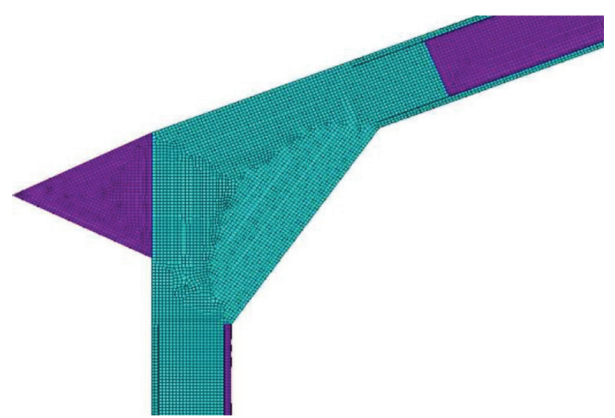

Figure 8: Finite element model for the frame.

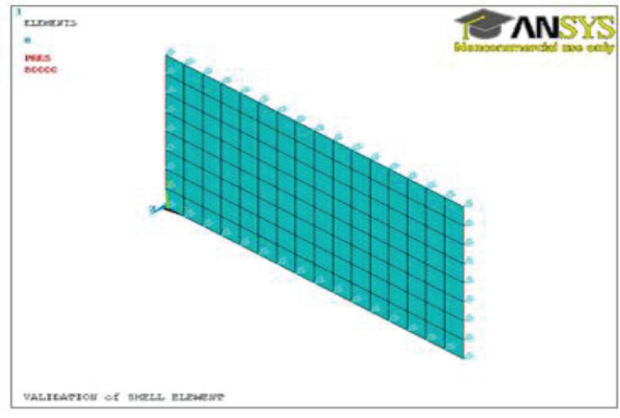

Figure 9. Plate model with shell elements (SHELL181).

The material was modelled as bilinear isotropic elastic-perfectly plastic. The inelastic behaviour of the steel elements was considered using the von Mises yield criterion as von Mises yield surface allows isotropic yielding. Geometric nonlinearities, large displacement and $\mathrm{P}-\delta$ effects were considered in the analyses.

The plate was modelled with element mesh size about $12.5 \mathrm{~mm}$ for a uniform mesh of 128 SHELL181 shell elements, as shown in Fig. 9.

For verification of the model, a nonlinear buckling analysis was carried out to predict the critical load for buckling of a thin flat plate. Where the load is increased until the solution fails to converge, indicating that the structure cannot support the applied load (or that numerical difficulties prevent solution). In this case, the nonlinear geometry (nonlinear elastic) is considered without counting for nonlinear materials (nonlinear plastic).

This analysis resulted in a value of $71.0 \mathrm{KN} / \mathrm{m}$ for the expected buckling load. This shows a good agreement with thin plate buckling theory that predicts it will buckle when the applied load is $75.9 \mathrm{KN} / \mathrm{m}$.

The nonlinear method is the more accurate type of buckling analysis as it predicts the buckling load when the plate starts to buckle. This result in a smaller value for the expected buckling load obtained by nonlinear buckling analysis compared with the thin plate buckling theory.

\subsection{Finite elements frame analysis results}

The force displacement diagram is shown in Fig. 11, the structure had a considerable nonlinearity as the displacement after yielding value about $47 \mathrm{~mm}$ with yielding value about $33 \mathrm{~mm}$. As shown in (Fig. 10) the structure appears to be buckling, in a lateral-torsional mode, at the right hand knee and failed due to the lateral-torsional buckling of the rafter and columns. The right side of the frame suffered worse torsional buckling than the left side because of the effect of the loading directions. The torsional buckling of structural members should be prevented in order to have a good seismic design. The improvement of the frame could be only in terms of frame members sections without considering the connections as the connections performed very well.

\subsection{Concluding remarks}

These results gave a general understanding for the behaviour of the frame structure under horizontal displacements, which should reflect the frame structure response and resistant to 


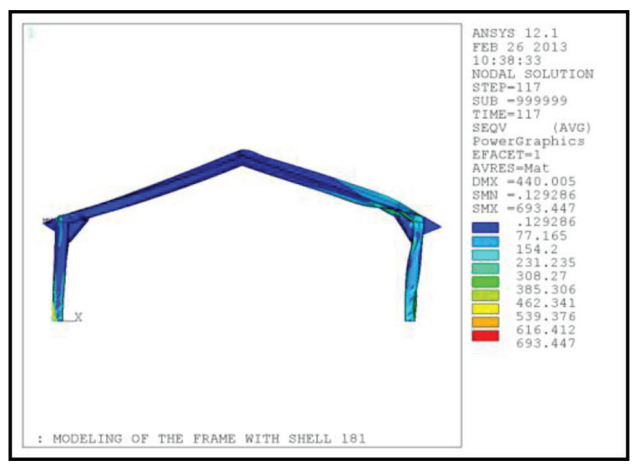

Figure 10. Von Mises stress (MPa).

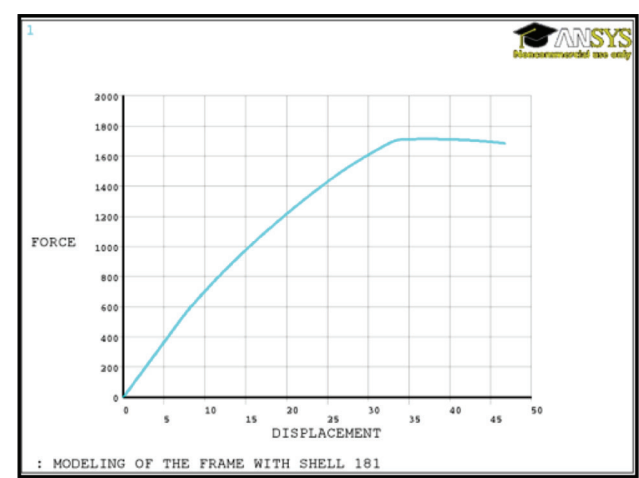

Figure 11. Force (N) vs. displacement (mm).

earthquake motion. The frame design in this study for the earthquake resistance will be the result of combining evaluation of structural performances by these numerical finite element investigations with check calculations based on EN 1993-1-3 [1] loading code.

The section used for the last model is built up cold-formed steel sections made from largest back-to-back lipped channel as detailed in present paper in section 3.1. The sections for column and rafter are chosen as result of the numerical finite element investigation, and then are checked by code calculation for different requirements to EN 1993-1-3 [1] and EN 1998-1 [2]. Use is made of EN 1993-1-3 [1] for cold-formed steel members and EN 1993-1-1 [6] for design of steel structures to estimate the loads on the frame structure within the use of EN 1998-1 [2] for the ductility class and behaviour factor for the proposed last model.

\section{ANALYTICAL CALCULATIONS TO EUROCODE}

\subsection{Earthquake analysis of frame to eurocode}

The elastic analysis of the buildings involved the analytical cold-formed light gauge steel model with respect to the steel strength and ductility class as it is steel grade S355 with ductility class low. The ductility class is used to estimate the behaviour factor, which is a reduction factor used for the estimation of the resistance to seismic forces.

The joints were assumed to be; fixed for column bases and rigid for beam to column. This model was analysed and the action effects for each individual member of the building were obtained for the two load combinations in eqns (1) and (2) according to Eurocode, using the commercially available structural analysis software (ANSYS).

$$
\begin{gathered}
E d=(1.35 G+1.5 Q) \\
E d=\left(G+\sum \varphi_{2, i}+E_{i}\right)
\end{gathered}
$$

The analysis for earthquake and the estimation for the forces for the initial design were carried out according to EC8 code. Both the equivalent lateral force procedure and the modal spectrum procedure were used for determination of base shear according to EN 1998-1 [2]. The shape of design spectrum obtained by EN 1998-1 [2] was as shown in Fig. 12. The value used was the value resulted from the static procedure after considering the torsional effects. 


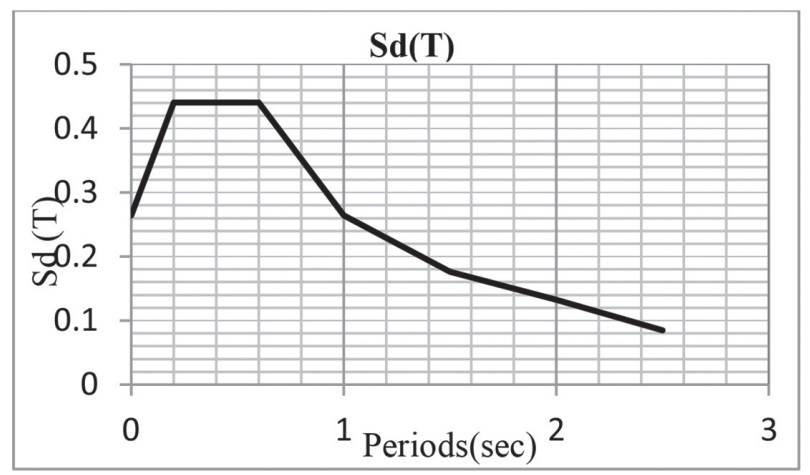

Figure 12. Design spectrum for elastic analysis to EN 1998-1 [3].

The imposed loads on the buildings were considered as a uniform load on the spans. Upon determination of the action effects per each element, the design of beam (rafter) or column section was carried out "'manually".

The second order effects (P- $\delta$ effects) were ignored according to EN 1993-1-1 [6] as it has been found that the resulting value of $\alpha_{\text {crest }}$ is greater than 10 , for that first order analysis used for the structure. Where $\alpha_{\text {crest }}$ is the factor by which the design loading would have to be increased to cause elastic instability in a global mode. Since the frame was sensitive to buckling in a sway mode, the global initial sway imperfection was allowed and according to EN 1993-1-1 [6].

\subsection{Design of frame members to eurocode}

In EN 1998-1 [2], light gauge steel or the thin-walled steel are classified as low dissipative structure, the ductility class, is recognised for low dissipative structural behaviour as low (DCL). According to EN (European Standard) EN 1998-1 [2], for low dissipative structures, the design forces may be calculated on the basis of an elastic global analysis without taking into account any significant non-linear material behaviour.

The frame structure, studied herein is a regular structural system which meets the criteria for regularity in plan and in elevation and satisfies the geometrical constraints of EN 1998-1 [2].

For dissipative zones in the case of columns, the normalised design axial force NEd for this frame structure conformed to $\frac{\mathrm{N}_{\mathrm{Ed}}}{\mathrm{N}_{\mathrm{pl}, \mathrm{Rd}}}<0.3$ which is well below the limiting values for the low DC building, as it is found to be 0.02 for the elastic design. Hand calculations for the design procedures of the frame structure was carried according to EN 1993-1-3 [1] and EN 1993-1-1 [6].

\subsection{Column design and verification}

The section 850x650x63x3 - back-to-back lip channel section - cold-formed steel grade S355 was selected for the column member and the verification of the member was carried out for the critical load combination. Since for design use of the critical load combination is made, the design actions for columns were those resulting from the seismic combination and, as pointed out earlier, the normalised design axial force $\mathrm{N}_{\mathrm{Ed}}$ was found to be well below the 
limiting values specified in Eurocode 8 for the low ductility class. Many checks for the section of column were carried out to verify the ability of the column to carry the service load during the service life of the building such as resistance of the cross-section for shear, compression and bending moment in accordance with EN 1993-1-3 [1] for cold-formed steel and EN 1993-1-1 [6] for steel. Columns also have been verified as having sufficient resistance against lateral and lateral torsional buckling in accordance with EN 1993-1-3 [1] and EN 1993-1-1 [6].

\subsection{Rafter Design \& Verification}

The section 750x500x53x3 - back-to-back lip channel section - cold formed steel grade S355 was selected for the rafter member and the verification of the member was carried out for the critical load combinations, as for the column member. The design of the rafters was performed for the gravity load combination $\mathrm{Ed}=(35 \mathrm{G}+1.5 \mathrm{Q})$, for the low ductility class examined, which yielded larger bending moments than the seismic load combination. Many checks for the section of rafter were carried out to verify the ability to carry the service load such as resistance of the cross section for shear, compression and bending moment in accordance with EN 1993-1-3 [1] for cold-formed steel and EN 1993-1-1 [6] for steel. Rafters also have been verified as having sufficient resistance against lateral and lateral torsional buckling in accordance with EN 1993-1-3 [1] and EN 1993-1-1 [6]. (These are of paramount importance for earthquake resistance).

\section{THE PROPOSED DESIGNED MODEL OF PORTAL FRAME STRUCTURE}

\subsection{Model description}

The model used herein is a result of calibration of the seismic design using numerical investigation and calculations to the design rules in the European codes specifications. The frame building model is frame of span $20 \mathrm{~m}$ with rigid joints and fixed at column bases, pitch $5^{\circ}$.The columns are $6 \mathrm{~m}$ high and the distance from ground level to the apex of the frame is approximately $6.875 \mathrm{~m}$ (see Fig. 4). The brackets for the joints for ridge and knees are $5 \mathrm{~mm}$ thickness from cold-formed steel (see Figs 13 and 14). The connection used here as same as

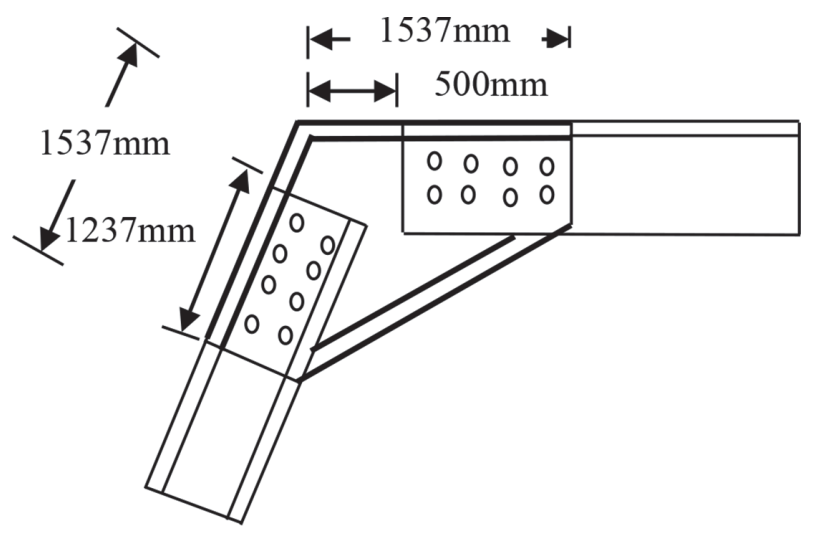

Figure 13. Knee arrangement for the last model. 


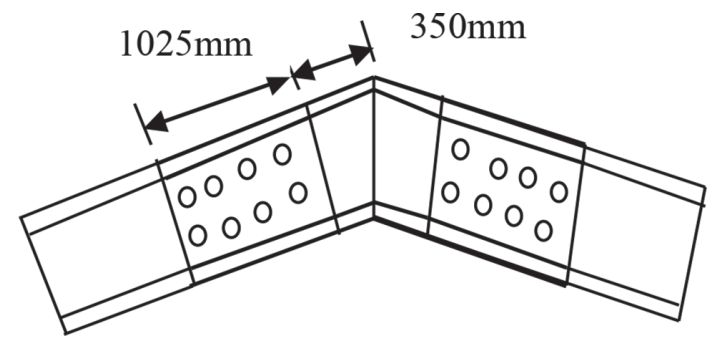

Figure 14. Ridge arrangement for the last model.

the connections used in the first model in Figs 6 and 7 for both ridge and knees as this arrangement of connections showed good performance when the frame model was tested to lateral displacements loading. The model was defined with the same materials properties, type of element, material modelling and finite element idealisation like first model using ANSYS software; to check response of the new proposed designed modified model of the frame structure for the nonlinear static analysis under increasing lateral displacements until the failure of the frame structure.

\subsection{Finite elements results of the proposed designed model}

Since the frame members are sensitive to buckling, the frame needed to be restrained to prevent lateral and lateral torsional buckling by providing the frame members with restraint members in areas sensitive to buckling. These restraints include purlins as beam (rafter) restraints and rails as column restraints.

The restraints include lateral restraint, torsional restrains and intermediate restraints. These effects have been applied in the finite element model for the light gauge steel portal frame in ANSYS as spring element known in ANSYS as COMBIN40. This spring element has one degree of freedom at each node, either a nodal translation, rotation, pressure, or temperature.

The analysis resulted in the absence of the torsional buckling of the frame sections and the failure was seen to be by the local buckling of the flange upper part of the right column with yielding of the column base due to buckling of the flange and the web of the column as shown in Figs 15 and 16. This caused the failure of the frame structure. The force displacement

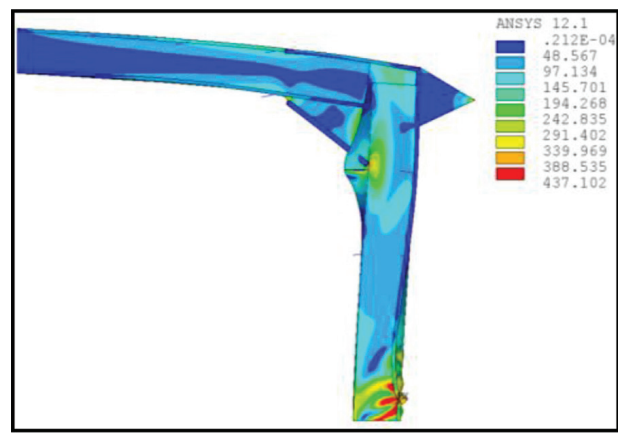

Figure 15: Von Mises stress (MPa) right.

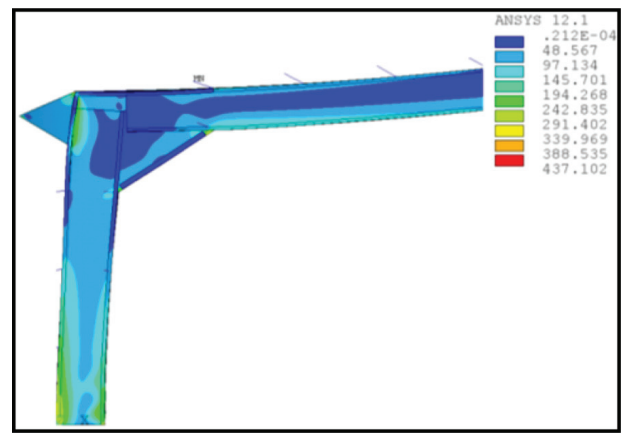

Figure 16: Von Mises stress (MPa) left. 


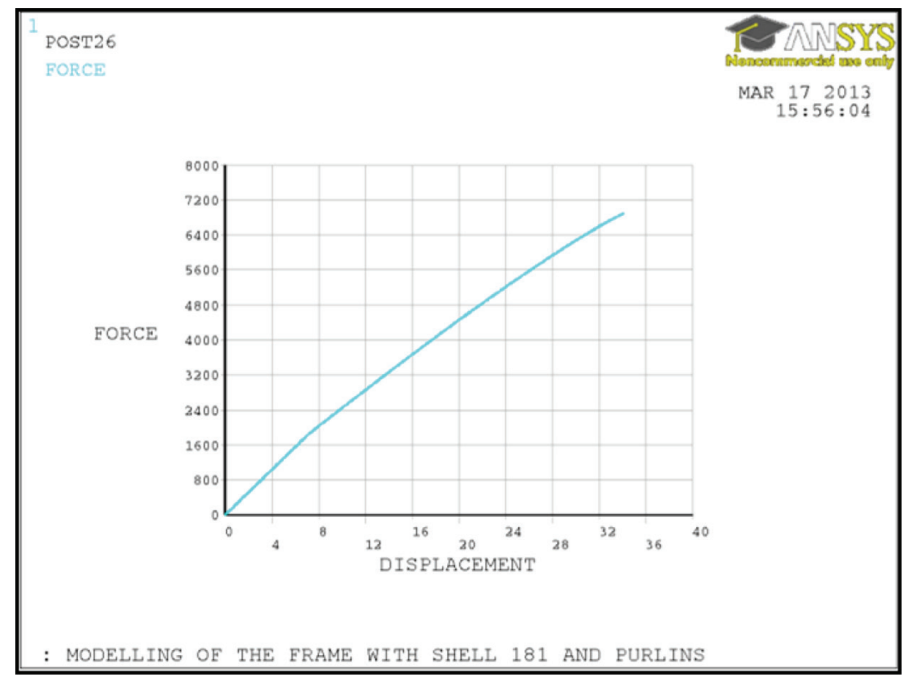

Figure 17: Force (N) vs. displacement (mm) diagram.

relationship showed ductility with value of $34 \mathrm{~mm}$ beyond the plastic zone and at the yielded point is $8 \mathrm{~mm}$ displacement as shown in Fig. 17. Due to the column buckling, a premature failure happened to the structure before yielding into plastic mechanism.

According to this result, the frame structure needs to be improved to be protected against this kind of premature failure which is not desirable in earthquake resistant structures.

\section{ONCLUSIONS}

From the first investigation, the importance of lateral restraints for this type of structure, when subject to horizontal forces or earthquake action, was noticeable: lateral torsional buckling is the main cause of failure for this type of structure, if it is not well restrained. Therefore, the design utilized lateral restraints directly or indirectly to the purlins.

The results of the numerical investigation combined with the code calculations checks resulted in an optimization of the model for the purpose of the study. The potential benefits of utilising light gauge steel or slender steel for the construction of portal frame buildings in earthquake prone areas were examined. The modes of failure of the designed frame structure were investigated with a three-dimensional detailed finite element model. This demonstrated that, as was expected, premature failure of the frame is due to buckling of the slender frame section profiles. Such a mode of failure is not desirable in an earthquake-resistant structure as the capacity drops very suddenly when the structure is overloaded. In contrast, a structure with more ductility has the capability to absorb energy and can better survive the shaking from the ground accelerations.

\section{REFERENCES}

[1] EN 1993-1-3. "Eurocode 3: Design of Steel Structures. Part 1-3: General Rules. Supplementary Rules for Cold-Formed Thin Gauge Members and Sheeting", CEN- European Committee for Standardization, 2006.

[2] EN 1998-1. "Eurocode 8: Design of Structures for Earthquake Resistance. Part 1: General rules, Seismic Actions and Rules for Buildings", CEN - European Committee for Standardization, 2004. 
[3] Dubina, D., Ductility and seismic performance of thin walled cold-formed steel structures. International Journal of Steel Structures, 4, pp. 209-222, 2004.

[4] Ono, T. \& Suzuki, T., Inelastic behaviour and earthquake-resistance design method for thin-walled metal structures. Proceedings on IABSE Coll. on Thin-Walled Metal Structures in Building, Stockholm, pp. 115-122, 1986.

[5] ANSYS, Inc. Structural analysis guide, Release 12.1, 2009.

[6] EN 1993-1-1., Eurocode 3: Design of Steel Structures. Part 1-1: General Rules and Rules for Buildings. CEN- European Committee for Standardization, 2005. 